\title{
Effect of the North Pacific Tropospheric Waveguide on the Fidelity of Model EI Niño Teleconnections
}

\author{
Ronald K. K. Li, Tim WoOllings, AND Christopher O'ReILly \\ Atmospheric, Oceanic and Planetary Physics, University of Oxford, Oxford, United Kingdom \\ ADAM A. SCAIFE \\ The Met Office Hadley Centre, and College of Engineering, Mathematics and Physical Sciences, \\ Exeter University, Exeter, United Kingdom
}

(Manuscript received 25 February 2019, in final form 27 March 2020)

\begin{abstract}
In a free-running climate model, DJF tropical-extratropical teleconnections are assessed and compared to observed teleconnections in reanalysis data. From reanalysis, the leading mode of covariability between tropical outgoing longwave radiation (OLR) and Northern Hemisphere extratropical geopotential height (Z500) is identified using maximum covariance analysis (MCA). This mode relates closely to the El Niño pattern. The GCM captures the tropical OLR well but the associated extratropical Z500 less well. The GCM climatology has an equatorward shifted North Pacific jet bias. We examine whether the difference in the teleconnection pattern is related to the GCM's jet bias. In both a ray-tracing analysis and a barotropic model, this jet bias is shown to affect the Rossby wave propagation from the tropical Pacific into the North Pacific. These idealized model results suggest qualitatively that the MCA difference is largely consistent with linear Rossby wave dynamics. While the basic state has a larger effect on the North Pacific MCA, a Rossby wave source (RWS) bias in the Caribbean has a larger effect on the North Atlantic MCA. The North Pacific jet bias is also proposed to affect the downstream propagation of waves from North America into the Caribbean, where it affects tropical RWS and the triggering of secondary waves into the North Atlantic. We propose that climatological biases in the tropics are one underlying cause of the jet bias. Our study may also help understand the results of other climate models with similar jet biases.
\end{abstract}

\section{Introduction}

One of the major drivers of tropical variability is $\mathrm{El}$ Niño-Southern Oscillation (ENSO), an ocean-atmosphere coupled phenomenon originating in the tropical Pacific. ENSO has global teleconnections in both the ocean and the atmosphere. The rearrangement of convection in the Walker circulation causes anomalous precipitation in other ocean basins (Dai and Wigley 2000) and anomalous divergence in the tropics drives Rossby waves into the extratropics to cause global atmospheric teleconnections (Trenberth et al. 1998). Changes in the Hadley and Walker cells, Rossby waves, and interactions between the quasi-stationary flow and storm tracks result in atmospheric bridges (Trenberth et al. 1998), which affect global ocean basins through surface heat

Corresponding author: Ronald K. K. Li, ronald.li@keble. oxfordalumni.org fluxes (Alexander et al. 2002). More recently, trends in tropical sea surface temperatures have also be shown to cause an interdecadal shift in ENSO extratropical teleconnection, partly through modifying the climatological atmospheric background circulation (O'Reilly et al. 2019).

Rossby waves are present on planetary scales in the extratropical troposphere and are responsible for global teleconnections. Early studies demonstrated the extratropical Rossby wave response to tropical diabatic heating, using simple barotropic and baroclinic models (e.g., Hoskins and Karoly 1981; Simmons 1982). Scaife et al. (2017) showed that stationary Rossby waves play an important role in seasonal forecasts via tropicalextratropical teleconnections, and that a highly significant fraction of prediction skill in wintertime seasonal forecasts (Scaife et al. 2014; Athanasiadis et al. 2017) can be explained by tropical rainfall variability and resultant poleward propagating stationary Rossby waves. 


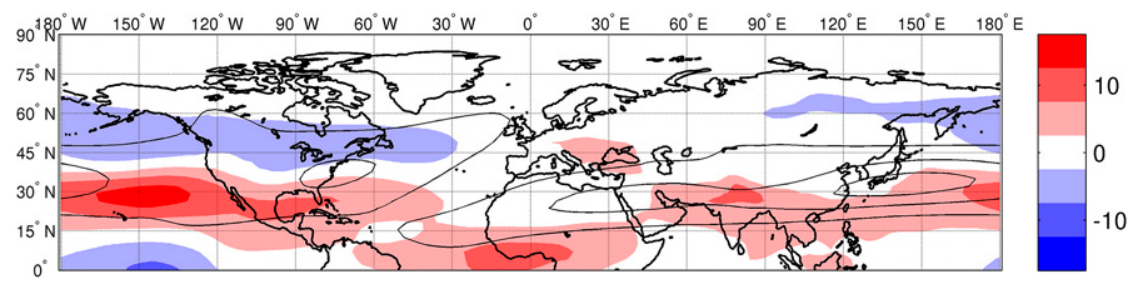

FIG. 1. The GCM North Pacific jet bias. Color shading shows the difference in DJF climatological 250-hPa zonal wind of the GCM minus reanalysis $\left(\mathrm{m} \mathrm{s}^{-1}\right)$. The black contour shows the reanalysis climatology, in $20 \mathrm{~m} \mathrm{~s}^{-1}$ intervals from $20 \mathrm{~m} \mathrm{~s}^{-1}$.

Extratropical Rossby waves can be triggered by the Rossby wave source (RWS) in the tropics and subtropics (Sardeshmukh and Hoskins 1988). These waves are sensitive to the extratropical jets, which act as waveguides (Hoskins and Ambrizzi 1993). The waveguides depend on the upper-level zonal wind structure (Hoskins and Karoly 1981). The tropicalextratropical teleconnection is not necessarily always from the tropics into the extratropics. On intraseasonal time scales, Liebmann and Hartmann (1984) found that while the dominant teleconnection in the western Pacific is via the tropics forcing Rossby waves into the extratropics, the other direction dominates in the eastern Pacific. Similar conclusions are also found for the Atlantic intertropical convergence zone using observations (Kiladis and Weickmann 1992) and GCMs (Kiladis and Feldstein 1994). Another possibility is that tropical variability could act as stochastic forcing to excite a primarily extratropical pattern of variability (e.g., Ding et al. 2011).

In this study we investigate the Met Office climate model (hereafter GCM). We find that there are differences between the model and observations in the leading mode of covariability. The model also exhibits a clear bias in the North Pacific jet (see Fig. 1). Based on the literature outlined above, we hypothesize that this jet bias may contribute to the difference in teleconnection pattern. The main purpose of this paper is to investigate this hypothesis. A secondary aim is to test the use of idealized models, to be introduced in section 2 , as tools to investigate such mechanisms.

We present our maximum covariance analysis of tropical-extratropical teleconnections (section 3) and examine the GCM jet and waveguide biases (section 4). By using Rossby wave ray tracing (section 4) and driving waves with a barotropic model (section 5), we find that the jet bias has a clear effect on wave propagation over the North Pacific and North America in these models. We then investigate the teleconnection to the North Atlantic sector (section 6). The cause of the GCM North Pacific jet bias is also discussed (section 7). Finally, we discuss how our results can have wider implications than just for this GCM (section 8).

\section{Data and methods}

\section{a. Data}

Chiodi and Harrison (2015) showed that global seasonal precipitation anomalies are more robustly associated with ENSO events when identified not by sea surface temperature (SST) but by outgoing longwave radiation (OLR). To diagnose the tropical part of the teleconnection, we use monthly mean top-ofatmosphere OLR from the NOAA OLR dataset (Liebmann and Smith 1996). OLR is an effective proxy of the atmospheric heating anomalies that drive atmospheric circulation anomalies elsewhere. To diagnose the extratropical part of the teleconnection, we use monthly mean geopotential heights at $500 \mathrm{hPa}$ from the NCEP-DOE Reanalysis 2 (Kanamitsu et al. 2002). The data we use are DJF seasonal means from 1980 to 2013 . We use the monthly Niño-3.4 index and the rotated principal component analysis-based monthly Pacific North America (PNA) index from the NOAA Climate Prediction Center (CPC).

We analyze the HadGEM3-GC3.0 control run (Williams et al. 2017), which is a free-running simulation with external forcing set to values from the year 2000 . The horizontal resolutions are $\mathrm{N} 216(60 \mathrm{~km})$ in the atmosphere and ORCA025 extended $\left(0.25^{\circ}\right)$ in the ocean. The vertical resolutions are 85 levels in the atmosphere and 75 levels in the ocean. The atmosphere module is fully coupled to ocean and land surface modules. Some known biases of the GCM include a residual asymmetric sea surface temperature bias with a cool Northern Hemisphere and warm Southern Ocean, an overly strong global hydrological cycle, and insufficient European blocking. Previous studies have also shown that the storm track is well simulated in this GCM, with just a slight deficit in intensity at the end of the Atlantic storm track (Williams et al. 2015, 2017). We analyze the DJF seasonal mean for 99 years. The reanalysis and the GCM 
datasets are interpolated to the same grid by a triangular truncation at wavenumber 42 (T42).

\section{b. Maximum covariance analysis}

Maximum covariance analysis (MCA) looks for patterns in two space-time datasets that explain the maximum fraction of the covariance between them (Wilks 2011). From the singular value decomposition of the covariance matrix, each pair of singular vectors is a mode of covariability between the fields. The correlation between the expansion coefficients of the two fields for one mode indicates how strongly related the coupled patterns of this mode are.

Each mode explains an amount of the overall squared covariance in the covariance matrix given by the square of the singular value. The squared covariance fraction (SCF) assesses the relative importance of each mode. If the typical error of a particular singular value is comparable or larger than the difference between the singular value and its closest neighbor, then the singular vectors are assumed to no longer be distinct modes (North et al. 1982).

Both the reanalysis and GCM data are weighted by the square root of the cosine of latitude to account for spherical geometry. The regions for MCA analysis are restricted to the circumglobal band between $15^{\circ} \mathrm{S}$ and $15^{\circ} \mathrm{N}$ for the OLR, and between $40^{\circ}$ and $90^{\circ} \mathrm{N}$ for the Z500. Results are similar when using 250-hPa geopotential heights, or slightly different MCA boxes, or standardized data. The second mode is not robust to subsampling of the reanalysis years into odd and even, so we focus on the leading mode only.

Significance of the difference between reanalysis and the GCM MCA is tested by a two-tailed Monte Carlo method. From the 99-yr GCM run, samples of 34 years, which correspond to the number of years of reanalysis, are drawn randomly without replacement. MCA is performed for those 34-yr GCM samples, and reanalysis MCA patterns are subtracted from each run. Since the polarity is arbitrary, we reverse the pattern in the subtraction whenever the spatial correlation between the patterns are negative. After repeating the sampling 1000 times, the significance at each grid point is deduced by where the zero value lies in the resulting distribution. A grid point with a significance of $99 \%$ means that the zero lies either within the smallest five or the largest five values at the two ends of the distribution. To account for the multiple hypothesis tests, we control the false discovery rate (Benjamini and Hochberg 1995; Wilks 2016) by choosing $\alpha_{\mathrm{FDR}}$ to be 0.10 . The result is that a $p$ value of 0.01 is used as a conservative threshold for the local tests, such that this $p$ value shows statistically significant differences in both OLR and Z500 with the multiple hypothesis testing accounted for.

\section{c. Rossby wave ray tracing}

Hoskins and Karoly (1981) developed the theory of barotropic Rossby wave ray tracing applied to a linearized nondivergent barotropic vorticity equation on a sphere. Kinematic wave theory gives that the zonal wavenumber $k$ and the frequency are constant along a ray. To satisfy the dispersion equation everywhere on the sphere, the meridional wavenumber has to vary along the ray. It is this variation that changes the propagation direction.

While meridional basic flow can sometimes alter interhemispheric propagation (Li et al. 2015), in our study of propagation from the tropics to the extratropics we take the simpliest linear barotropic dispersion relation with no meridional basic flow. We use a $60^{\circ}$ sectoral zonal running averaging on the climatological $250-\mathrm{hPa}$ zonal wind. The zonal averaging represents a typical wave scale (Scaife et al. 2017; Ayarzagüena et al. 2018), but results are similar when omitting the averaging. We calculate the stationary wavenumber $K_{s}$ at every gridpoint from this smoothed climatological wind (Hoskins and Karoly 1981),

$K_{s}=\left(\frac{\beta_{M}}{\bar{u}_{M}}\right)^{1 / 2}=\left[\frac{\frac{2 \Omega}{a} \cos ^{2} \phi-\frac{\partial}{\partial y} \frac{1}{\cos ^{2} \phi} \frac{\partial}{\partial y}\left(\frac{\bar{u}}{\cos \phi} \cos ^{2} \phi\right)}{\frac{\bar{u}}{\cos \phi}}\right]^{1 / 2}$,

where $\beta_{M}$ is $\cos \phi$ times the meridional gradient of the absolute vorticity on the sphere, and $\bar{u}_{M}$ is the basic zonal velocity on the Mercator projection on the sphere. To sample the sensitivity to the starting position of a ray, we also plot an ensemble of eight other rays located around a square of $5^{\circ}$ in both longitude and latitude centered on the first ray. For the reanalysis experiments, we use NCEP2 winds.

\section{d. Barotropic model}

The barotropic model (O'Reilly et al. 2018) is based on Hoskins and Ambrizzi (1993). It integrates the damped barotropic vorticity equation

$$
\left(\frac{\partial}{\partial t}+\mathbf{V}_{\Psi} \cdot \nabla\right) \zeta=F-\lambda \zeta-\mu \nabla^{4} \zeta
$$

where $\mathbf{V}_{\Psi}$ is the rotational velocity, $\zeta$ is the absolute vorticity on the sphere, $\lambda$ is a linear damping with a time scale of around 10 days, and $\mu$ is a biharmonic diffusion coefficient of $5 \times 10^{16} \mathrm{~m}^{4} \mathrm{~s}^{-1}$. 
(a) Reanalysis MCA OLR

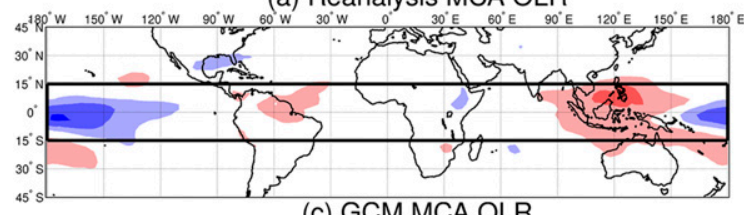

(c) GCM MCA OLR

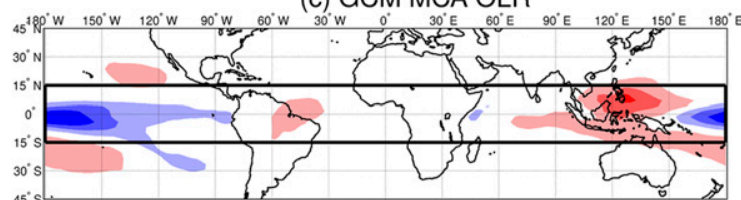

(e) MCA OLR difference

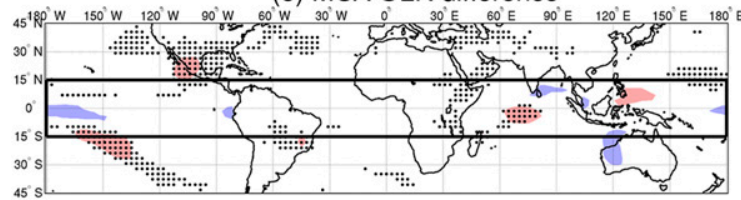

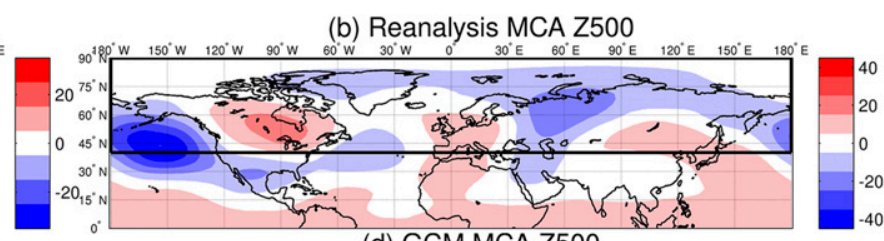

(d) GCM MCA Z500

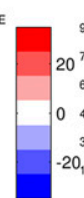

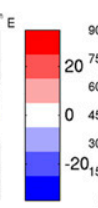

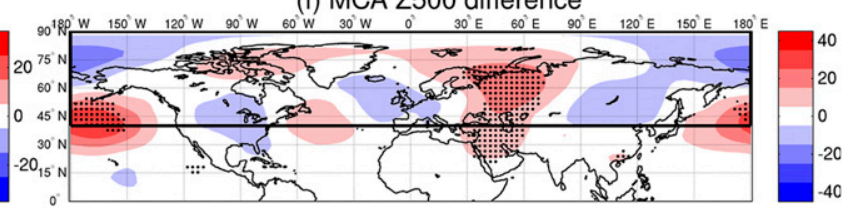

FIG. 2. Tropical-extratropical teleconnections. MCA leading mode patterns of (left) homogeneously regressed OLR and (right) heterogeneously regressed Z500 for (a),(b) reanalysis and (c),(d) GCM. Boxes indicate the MCA regions. The color shading for OLR is $10 \mathrm{~W} \mathrm{~m}^{-2}$ per standard deviation in the OLR time series, and for Z500 is $10 \mathrm{~m}$ per standard deviation in the OLR time series. (e),(f) The difference of the GCM minus reanalysis, with regions above $99 \%$ significance dotted.

The term $F$ is a constant forcing, and is expressed as $\bar{F}+S^{\prime} ; \bar{F}$ is the sign-reversed quantity obtained from the first time step change in the absolute vorticity in an experiment not forced by any Rossby wave source (RWS). Therefore, for each basic state used in this study (either reanalysis or GCM), a different value of $\bar{F}$ is applied in order to maintain the chosen basic state. The RWS is calculated using the expression from Sardeshmukh and Hoskins (1988),

$$
\mathrm{RWS}=-\nabla \cdot\left(\mathbf{V}_{\chi} \zeta\right)=-\mathbf{V}_{\chi} \cdot \nabla \zeta-\zeta \nabla \cdot \mathbf{V}_{\chi},
$$

where the first term on the right is the vorticity advection by the divergent wind and the second term is the vortex stretching, and $\mathbf{V}_{\chi}$ is the divergent wind. We calculate the RWS from daily winds, but using monthly winds is similar when averaging the RWS over the winter season. The term $S^{\prime}$ is obtained from linearly regressing the RWS onto the standardized expansion coefficient of the MCA tropical OLR leading mode. We isolate the tropical RWS by only retaining values within $15^{\circ} \mathrm{N}$ and $15^{\circ} \mathrm{S}$, or $30^{\circ} \mathrm{N}$ and $30^{\circ} \mathrm{S}$. We multiply the RWS by $10^{-6}$ to make the calculation effectively linear (Hoskins and Ambrizzi 1993), and the model response is scaled back up by $10^{6}$. This allows us to look at the most basic, linear wave propagation without any nonlinear complications, for example the wave interacting with itself. For our cases, however, the results are similar without scaling down the RWS. We use the climatological basic states on $250 \mathrm{hPa}$, similar to O'Reilly et al. (2018). This setup allows us to investigate the propagation of stationary Rossby waves from a tropical forcing that is stationary in time, on a basic state that is stationary in time. We present the quasi-stationary results by averaging between days 7 and 10 . For the reanalysis experiments, we use NCEP2 winds. A caveat of specifying the RWS in the barotropic model is that it may contain some secondary sources from the waves themselves.

\section{Tropical-extratropical covarying patterns}

MCA has been traditionally applied to study teleconnections (e.g., Wallace et al. 1992; Ding et al. 2011; O'Reilly et al. 2018). We apply MCA on the tropical OLR and the Northern Hemisphere extratropical Z500. Figures $2 \mathrm{a}-\mathrm{d}$ show the regressed OLR and Z500 patterns onto the OLR standardized expansion coefficients of the leading MCA modes, of reanalysis and the GCM. The homogeneous regression maps (Figs. 2a,c,e) show the OLR spatial patterns whose polarity and amplitude are represented by the OLR expansion coefficients. The heterogeneous regression maps (Figs. 2b,d,f) show how well the grid point values of the Z500 are associated with the OLR expansion coefficient. This leading mode explains a large fraction of the covariance in both reanalysis and the GCM (Fig. 3) and is separated from the second mode, according to North's rule (North et al. 1982). The correlation between the leading mode expansion coefficients of OLR and Z500 is 0.74 in reanalysis and 0.72 in GCM, indicating a strong and consistent coupling between OLR and Z500 in each dataset individually.

The reanalysis OLR pattern (Fig. 2a) shows reduced OLR over the tropical central Pacific and increased OLR 
(a) Reanalysis

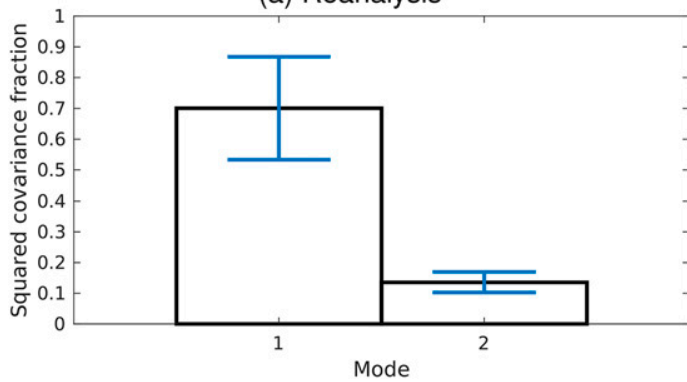

(b) GCM

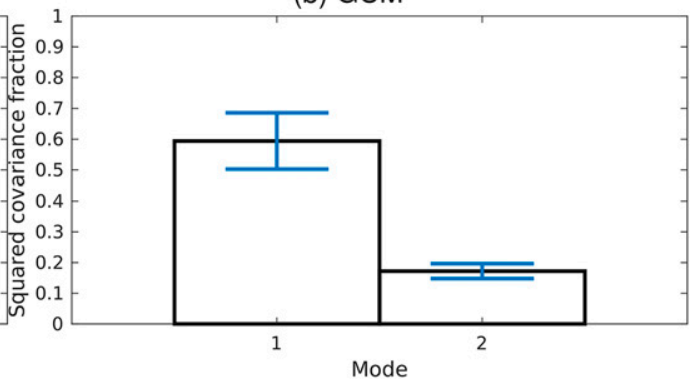

FIG. 3. Fractions of covariance explained by the MCA modes. The squared covariance fraction (SCF) and errorbars of the two leading MCA modes in (a) reanalysis and (b) the GCM.

over the Maritime Continent, resembling closely the positive phase of ENSO. This is similar to the strong El Niño event OLR pattern in DJF 1986/87 (Trenberth et al. 1998, Fig. 3b therein). The expansion coefficient of the reanalysis OLR strongly correlates with the oceanic Niño-3.4 index (Huang et al. 2015) (Table 1), confirming that the MCA is capturing a lot of variability associated with ENSO.

The coupled Z500 pattern (Fig. 2b) is strongest in the extratropical Pacific. There is a strong correlation with the Pacific-North America pattern (PNA) from CPC (Table 1), although our pattern is shifted to the east and also more hemispheric than the PNA from CPC. Our signal shows a strong wave-like anomaly over the North Pacific and North America, with a weaker signal in the North Atlantic and Europe. Z500 also strongly correlates with the Niño-3.4 index (Table 1). These patterns suggest that the leading mode of seasonal tropicalextratropical covariability is the ENSO.

While the MCA is a linear statistical method, there are known asymmetries in ENSO between its positive and negative phases (Hoerling et al. 1997). To compare our linear MCA to the asymmetric ENSO, Fig. 4 shows composites of the OLR and Z500 for the five most positive and the five most negative years of the MCA mode one OLR time series. While the center of enhanced deep convection lies east of the date line during El Niño, the center of suppressed deep convection lies west of the date line during La Niña. The OLR signal in the tropical eastern Pacific during El Niño is also not seen during La Niña. Corresponding to this westward shift in the La Niña tropical OLR pattern compared to El Niño, the La Niña extratropical Z500 pattern is also shifted westward compared to El Niño. While similar in many aspects, these composites hence reveal some asymmetries between the positive and negative phases. By focusing on the MCA patterns (Figs. 2a,b), the analysis results are more directly applicable to El Niño states than to La Niña.
The GCM OLR pattern (Fig. 2c) has a spatial correlation of 0.94 over the tropics with the reanalysis OLR pattern, and the GCM Z500 pattern (Fig. 2d) has a spatial correlation of 0.62 over the extratropics with the reanalysis Z500 pattern, suggesting the GCM can capture this mode of covariability. However, both the low heights near the Aleutian Islands and the high heights over Canada are weaker.

Figures $2 \mathrm{e}$ and $2 \mathrm{f}$ show the difference in the patterns between the GCM and reanalysis. Both datasets have very similar OLR but less similar Z500. The Z500 difference pattern is similar to the inverse of the reanalysis Z500 pattern, but with a more distinct zonal wavenumber $k=3$ pattern. This suggests that the extratropical covariability with El Niño in the GCM is too weak, especially in the $k=3$ component, which will also be shown in Figs. 5b and 5d.

To facilitate comparison between the Z500 patterns and the ray tracing analysis by wavenumber in the next section, we Fourier decompose the Z500 patterns into zonal wavenumbers from 0 to 4 . For both reanalysis and $\mathrm{GCM}$, the polar latitudes are dominated by $k=0$ and $k=1$, while the midlatitudes are dominated by $k=2$, $k=3$, and $k=4$. This agrees with the climatological $K_{s}$ that decreases from the equator to the pole. Among the midlatitude wavenumbers 2 to 4 , we focus on the $k=2$ and $k=3$ components (Fig. 5), which together well approximate the full field in the midlatitudes.

TABLE 1. Correlations of reanalysis MCA mode with known indices. Temporal correlations between the reanalysis MCA leading mode OLR and Z500 expansion coefficients, and the Niño-3.4 and PNA indices. All correlations are significant at the $p=0.01$ level.

\begin{tabular}{lcc}
\hline \hline & Niño-3.4 & PNA \\
\hline Reanalysis OLR & 0.94 & 0.49 \\
Reanalysis Z500 & 0.68 & 0.67 \\
Niño-3.4 & - & 0.57 \\
\hline
\end{tabular}



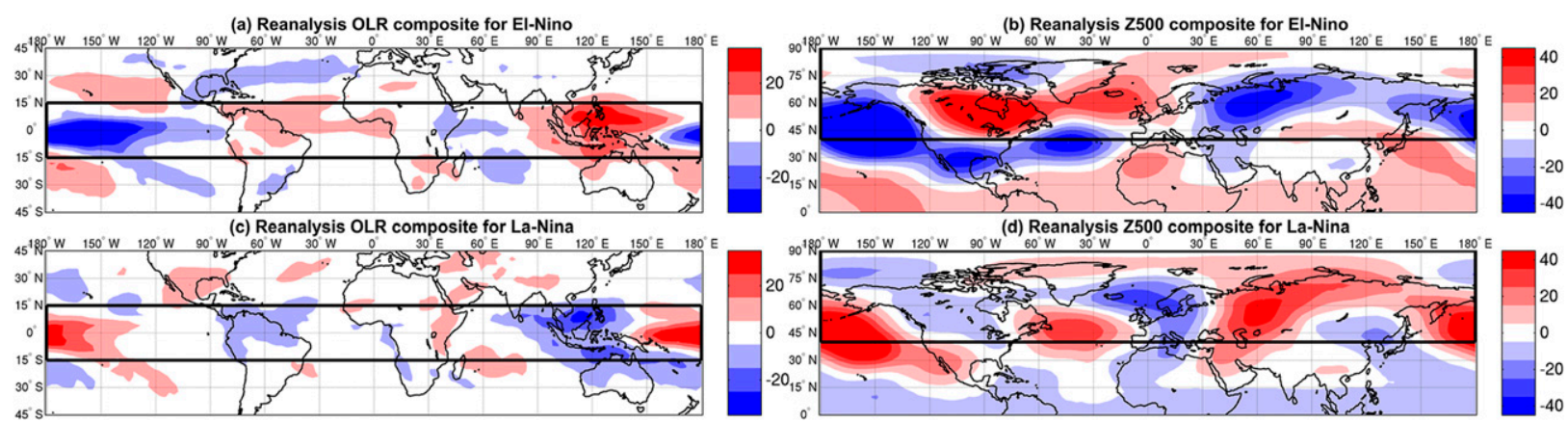

FIG. 4. ENSO composites. Composites of (a),(c) reanalysis OLR and (b),(d) Z500 for the (top) top five El Niño and (bottom) top five La Niña winters. The boxes are the same as the MCA boxes to allow for easier comparison with Figs. 2a and $2 \mathrm{~b}$.

The GCM $k=2$ amplitude maximum is at a lower latitude (around $30^{\circ} \mathrm{N}$ in Fig. 5c) than in reanalysis (around $45^{\circ} \mathrm{N}$ in Fig. 5a) and is also weaker. The $k=3$ amplitude is also weaker in the GCM (Fig. 5d) than in reanalysis (Fig. 5b). The Z500 difference between the MCAs (Fig. 2f) is captured well by just the $k=2$ and $k=3$ components (Fig. 5e). The higher heights south of the Aleutian Islands and the lower heights near the central North America in the MCA difference (Fig. 2f) are well captured. Next, we investigate whether errors in the tropical-extratropical teleconnection through Rossby wave propagation from the tropics, in particular the $k=2$ and $k=3$ components of the waves, can explain this MCA difference.

\section{Effect of jet bias on ray paths}

The strongest jet bias in the GCM is in the North Pacific where the modeled jet is shifted equatorward (Fig. 1). We shall discuss the possible cause of the jet bias in section 7. For now, we focus on the jet bias consequence rather than its cause.

Figure 6 shows the ray tracings and the climatological $K_{s}$ in reanalysis and the GCM. The rays are started in the tropical Pacific because this is the El Niño convection major center of action. The North Pacific jet bias causes the local meridional gradient of the absolute vorticity to decrease more rapidly than in reanalysis, resulting in lower turning latitudes for $k=2$ (Fig. 6c) and $k=3$ waves (Fig. 6d). These suggest that $k=2$ and $k=3$ waves propagating poleward into the North Pacific on the GCM basic state may reflect equatorward at a lower latitude than in reanalysis, thus not propagating as strongly in the midlatitudes.

In the reanalysis basic state, the majority of the $k=2$ (Fig. 6a) and $k=3$ ensemble members (Fig. 6b) propagate across parts of North America. The $K_{s}=2$ contour is lower in latitude in the North Pacific near $150^{\circ} \mathrm{W}$ in the GCM than in reanalysis, reflecting the $k=2$ rays equatorward much earlier thus not reaching North America. The $K_{s}=3$ contour is also lower in latitude in the $\mathrm{GCM}$ along $150^{\circ}-120^{\circ} \mathrm{W}$, reflecting the $k=3$ rays equatorward much earlier. While the difference in the $k=3$ ray paths between the basic states is similar when repeating the ray tracing slightly eastward from $160^{\circ} \mathrm{W}$ $15^{\circ} \mathrm{N}$ (not shown), the difference in the $k=2$ ray paths is reduced, suggesting the difference in the $k=3$ ray paths is more robust to the different starting locations.

To conclude, ray tracing suggests that poleward propagating Rossby waves of zonal wavenumbers 2 and 3 reflect equatorward at a lower latitude in the GCM basic state compared to reanalysis. This can result in weaker propagation and hence weaker amplitude of these components in the midlatitudes, consistent with the weaker extratropical teleconnections seen in the GCM.

\section{Effect of jet and wave source biases on barotropic experiments}

Figure 7a shows the reanalysis RWS regressed onto the reanalysis MCA leading mode OLR standardized expansion coefficient. In the tropics, large areas of relatively strong RWS are seen between $150^{\circ} \mathrm{E}$ and $150^{\circ} \mathrm{W}$ in the Pacific, with a negative source at around $15^{\circ} \mathrm{N}$ and a positive source near the equator. This zonally elongated meridional dipole of RWS is also identified in Scaife et al. (2017, Fig. 7c therein), who showed the RWS anomalies associated with heavy precipitation in the tropical east Pacific similar to El Niño. The heating generates large divergence in the upper troposphere. The associated anomalous divergent wind acts on the climatological gradient of relative vorticity and generates anomalous vorticity via the advection term in Eq. (3). RWS in the subtropics is larger than in the tropics, due to the more intense horizontal vorticity gradients closer to the jets, and also due to the proximity to the exratropical waves themselves and associated 
(a) MCA reanalysis $\mathrm{k} 2$
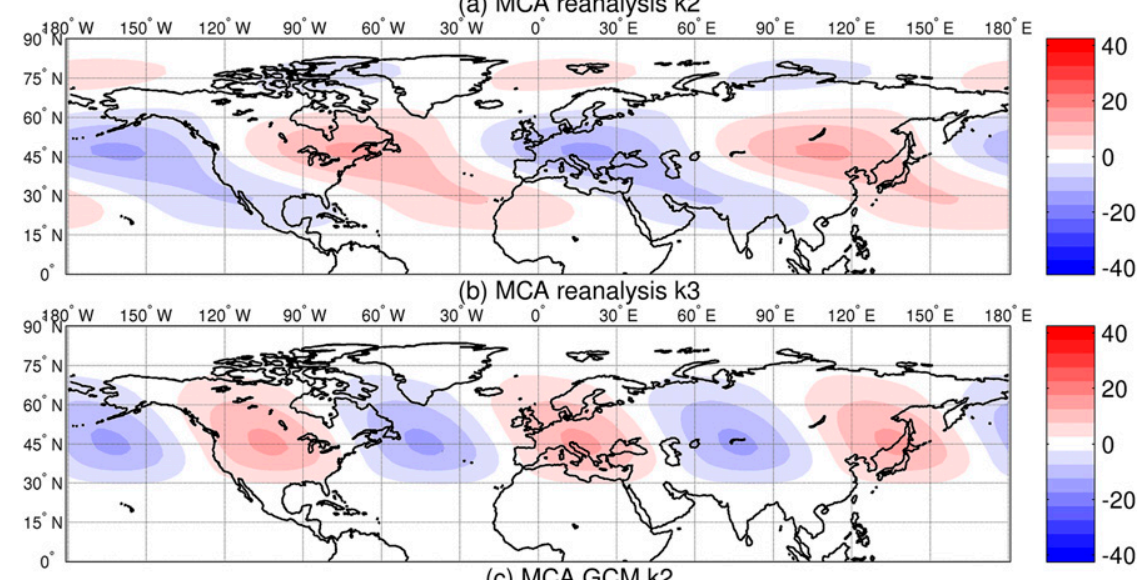

(c) MCA GCM k2

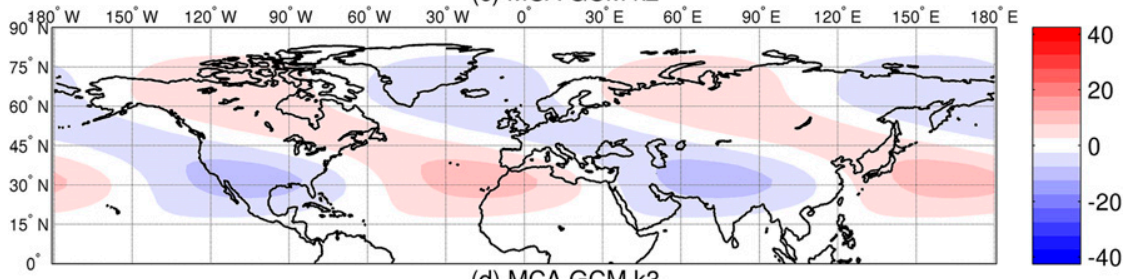

(d) MCA GCM k3

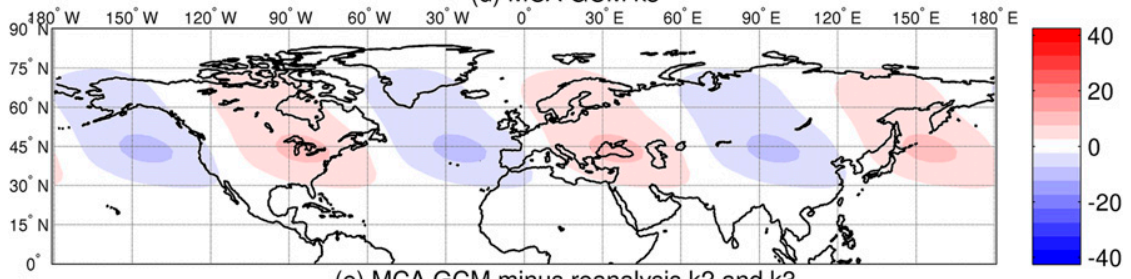

(e) MCA GCM minus reanalysis $\mathrm{k} 2$ and $\mathrm{k} 3$

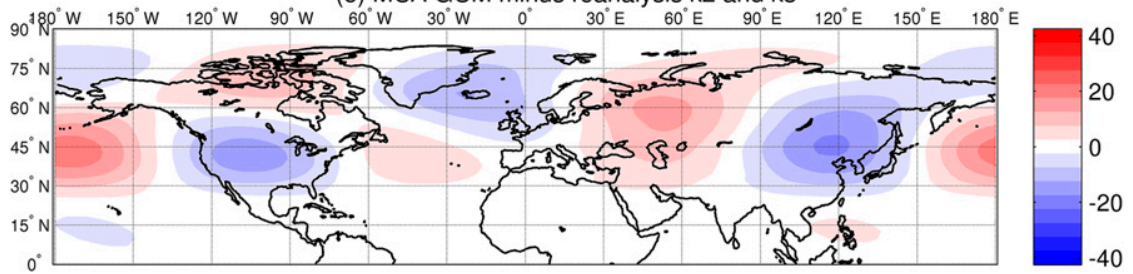

FIG. 5. Fourier analysis of MCA. Fourier decomposition of the reanalysis MCA Z500 pattern (Fig. 2b), into zonal wavenumbers (a) 2 and (b) 3. (c),(d) As in (a) and (b), but for the GCM MCA Z500 pattern (Fig. 2d). (e) The sum of the Fourier components $k=2$ and $k=3$ of the MCA Z500 difference (Fig. 2f). Contouring is every $5 \mathrm{~m}$.

anomalous vorticity. Since we are interested in the propagation of waves from the tropics, we refrain from including any extratropical RWS in the barotropic model as forcing. RWS truncated at $15^{\circ}$ on both sides of the equator is used in this section, but the results are qualitatively similar using $30^{\circ}$.

We first investigate whether the barotropic model can reproduce the reanalysis MCA. Figure 8a shows the barotropic model response using the reanalysis RWS (Fig. 7a) on the reanalysis basic state. Although the response matches in the North Pacific and North America with the observed MCA in Fig. 2b, it does not match well farther downstream. This comes mainly from the mismatch in the $k=0$ and $k=1$ components (not shown). A possible reason for the $k=0$ mismatch is that the barotropic model lacks stratospheric processes, which can have downward propagating signals in the zonal mean into the troposphere (Ineson and Scaife 2009; Bell et al. 2009). Another likely reason for the $k=1$ mismatch is the limitation of only having one pressure level in the barotropic model for wave propagation.

The barotropic model has a larger $k=1$ mismatch above $60^{\circ} \mathrm{N}$. Rossby waves typically propagate strongest along large isentropic potential vorticity gradient regions at the tropopause. The higher latitudes can be reached most readily by $k=1$ instead of $k=2$ and $k=3$ 
(a) Reanalysis k2
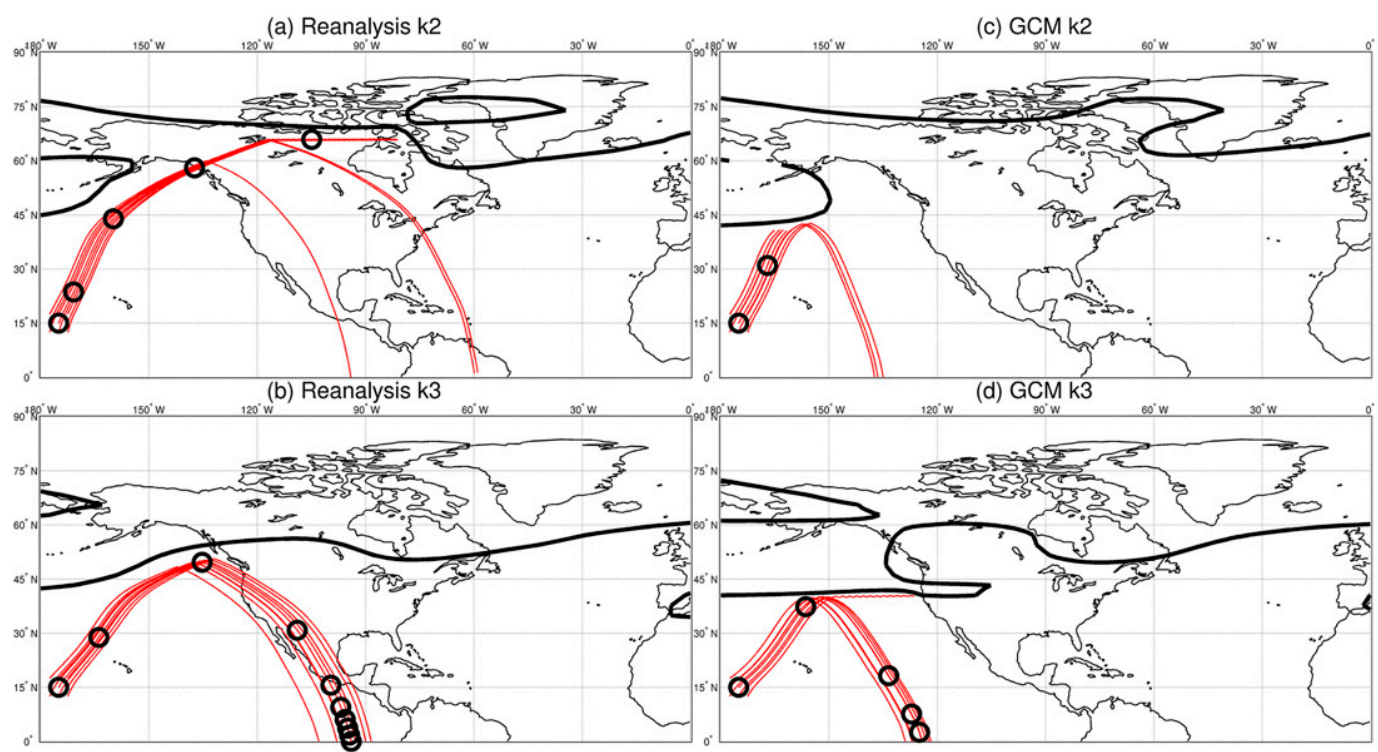

FIG. 6. Rossby wave ray tracings. (a) Ray tracing of the $k=2$ ray starting at $15^{\circ} \mathrm{N}, 175^{\circ} \mathrm{W}$, using $60^{\circ}$ zonally smoothed reanalysis basic state. The corresponding $K_{s}=2$ contour is in black. Each ensemble ray is in red, and black circles are superimposed daily on the central ray. (b) As in (a), but for the $k=3$ ray. (c),(d) As in (a) and (b), but using the GCM basic state.

waves in our tropical wave-making experiments, and at higher latitudes the tropopause dips down steeper than the 250-hPa level (Hoinka 1998). It is likely that $k=1$ waves more readily cross the two-dimensional jet and propagate into the high latitudes in the barotropic model.

In the barotropic model, the $k=2$ and $k=3$ components on the reanalysis basic state (Figs. 8e,f) match well with the reanalysis MCA (Figs. 5a,b). Although the barotropic model cannot fully reproduce the reanalysis MCA pattern, it can reproduce the $k=2$ and $k=3$ components, which are the important components in the MCA that we have been focusing on. Therefore, it is sufficient to focus on the barotropic model for our study.

Next, we compare the responses between the two basic states. Figure $8 \mathrm{~b}$ shows the full response using the

(a) Reanalysis regressed RWS

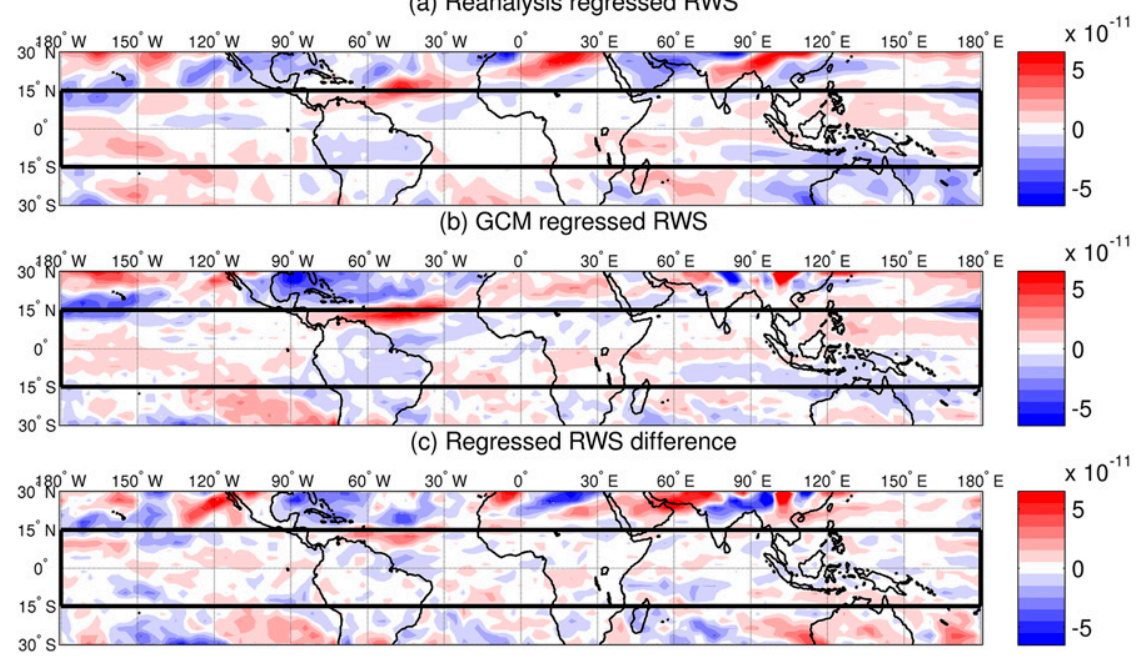

FIG. 7. Barotropic model Rossby wave sources. (a) Reanalysis Rossby wave source $\left(\mathrm{s}^{-2}\right)$ regressed onto the reanalysis MCA leading mode OLR standardized expansion coefficient. The box shows the $15^{\circ} \mathrm{N}-15^{\circ} \mathrm{S}$ region used. (b) The GCM RWS regressed onto the GCM MCA leading mode OLR standardized expansion coefficient. (c) Difference in RWS [(b) minus (a)]. 
(a) Barotropic reanalysis full
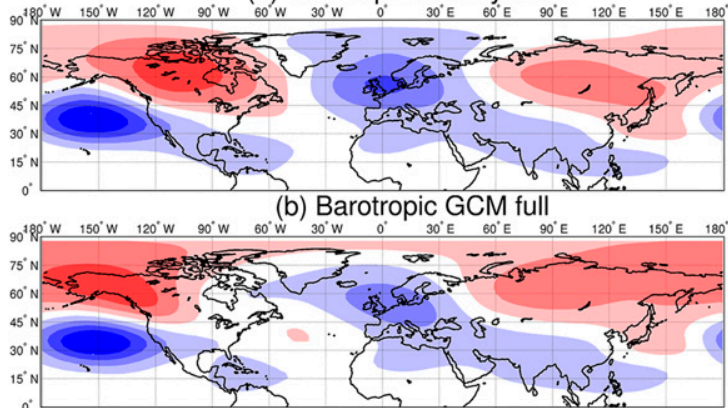

(c) Barotropic GCM minus reanalysis ful

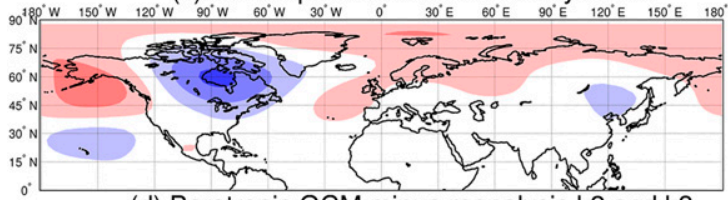

(d) Barotropic GCM minus reanalysis k2 and k3

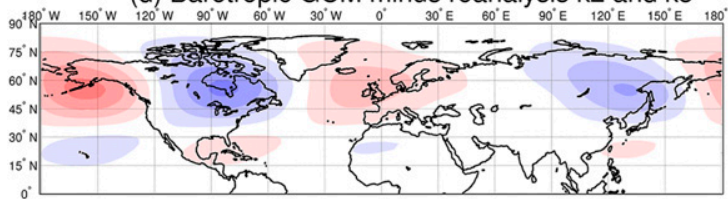

\section{西}

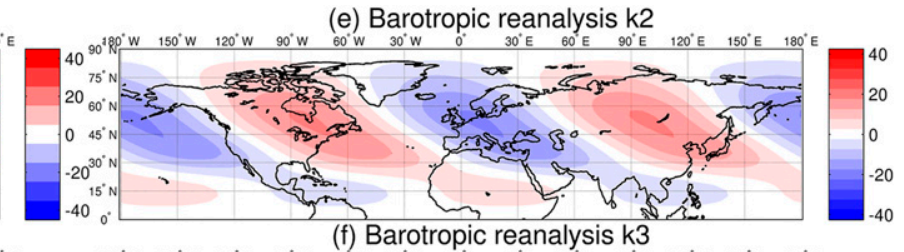

(e) Barotropic reanalysis k2

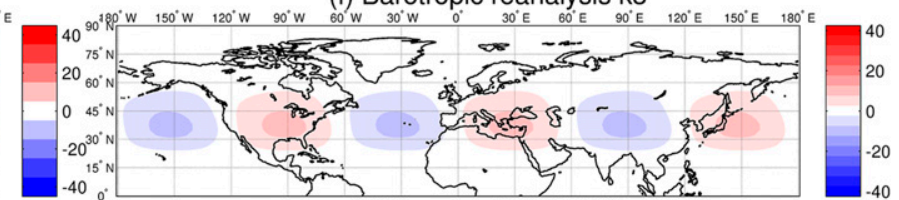

(g) Barotropic GCM k2

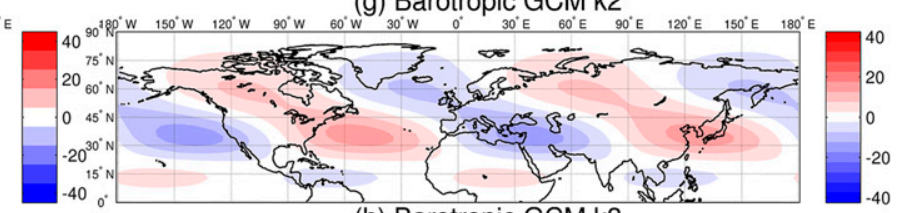

(h) Barotropic GCM k3

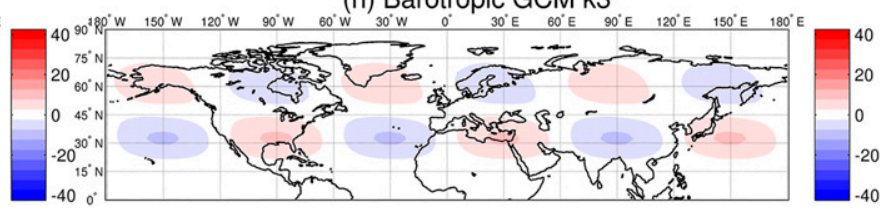

FIG. 8. Barotropic model geopotential height responses. (a),(b) Full response (m) using reanalysis forcing from Fig. 7 a between $15^{\circ} \mathrm{N}$ and $15^{\circ} \mathrm{S}$, on the basic states of reanalysis in (a) and the GCM in (b). The difference of the GCM minus reanalysis response is shown for (c) full and (d) only $k=2$ and $k=3$. (e),(f) The $k=2$ and $k=3$ components, respectively, of (a); (g),(h) the $k=2$ and $k=3$ components of (b). Contouring is every $10 \mathrm{~m}$ for (a)-(c) and $5 \mathrm{~m}$ for (d)-(h).

reanalysis RWS again but on the GCM basic state. As for reanalysis, the full response does not match well to the GCM MCA in Fig. 2d. The mismatch is again mainly due to the $k=0$ and $k=1$ components, and the $k=2$ and $k=3$ components in the barotropic experiment (Figs. 8g,h) match better to the $k=2$ and $k=3 \mathrm{com}$ ponents in the GCM (Figs. 5c,d).

Under the GCM basic state, the largest amplitude of the $k=2$ signal is at around $35^{\circ} \mathrm{N}$ (Fig. $8 \mathrm{~g}$ ), which is farther south than with the realistic basic state case where it occurs around $50^{\circ} \mathrm{N}$ (Fig. 8e). The largest amplitude of the $k=3$ signal is also farther south (Fig. 8h). Although it seems that there is another $k=3$ wave of opposite phase at the higher latitude of $60^{\circ} \mathrm{N}$ (Fig. 8h), closer inspection reveals that it is connected to the wave maxima at the lower latitude with a northwest-southeast tilted phase plane. For the same tropical RWS forcing in the barotropic model, both the $k=2$ and $k=3$ waves propagate to lower latitudes and are also weaker on the GCM basic state compared to the reanalysis basic state, in agreement with the ray tracing calculations earlier.

Finally, Fig. $8 \mathrm{~d}$ shows the sum of the $k=2$ and $k=3$ components from the difference map in Fig. 8c. Although the wave pattern shown in the differences in the barotropic model in Fig. $8 \mathrm{~d}$ is at a higher latitude near $60^{\circ} \mathrm{N}$ than that in the MCA near $45^{\circ} \mathrm{N}$ in Fig. $5 \mathrm{e}$, over the North Pacific and North America it mostly agrees with the MCA, with lower heights over eastern Russia, higher heights over the North Pacific, and lower heights over North America. Farther downstream over western Russia near $60^{\circ} \mathrm{E}$, the barotropic model cannot reproduce the higher heights in the MCA. Closer inspection reveals that whereas the $k=3$ difference between the two basic states in the barotropic model matches very well to the $k=3$ difference between the two MCAs, the $k=2$ difference matches less well. Therefore, while the barotropic model shows different propagation of $k=2$ and $k=3$ waves that are consistent with ray tracing, it further shows that it is the different propagation of $k=3$ that best explains the MCA difference.

Returning to our choice of the tropical forcing, so far we have been using the RWS from reanalysis. However, Fig. 2e shows that there are small differences in OLR between reanalysis and the GCM. This raises the question of whether these small differences in the tropical forcing affect our results. Therefore, we also tried using the $15^{\circ} \mathrm{N}-15^{\circ} \mathrm{S}$ GCM RWS from Fig. $7 \mathrm{~b}$ in the above experiments. The results are found to be similar (not shown), showing that the small differences in the tropical forcing cannot explain the MCA difference in the Pacific-North American region. 
(a) Barotropic,15N RWS bias,reanalysis state

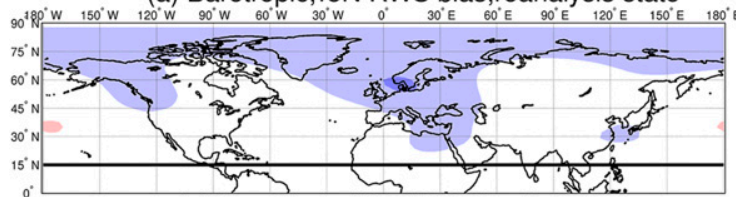

(b) Barotropic, $15 \mathrm{~N}$ RWS bias, GCM state

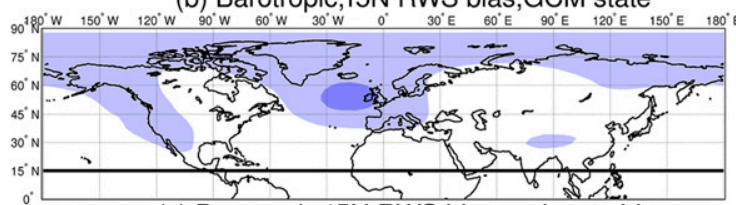

(c) Barotropic,15N RWS bias and state bias

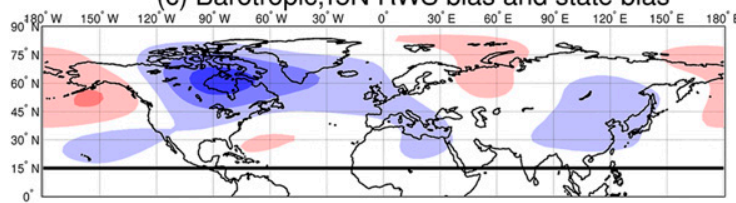

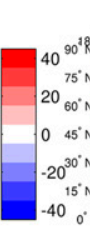

(d) Barotropic,30N RWS bias, reanalysis state

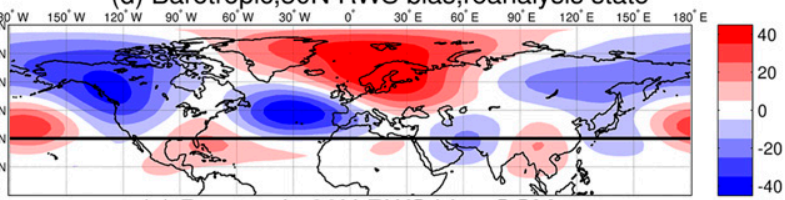

(e) Barotropic,30N RWS bias,GCM state
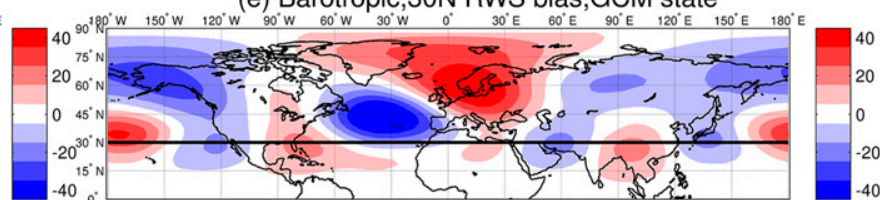

(f) Barotropic,30N RWS bias and state bias

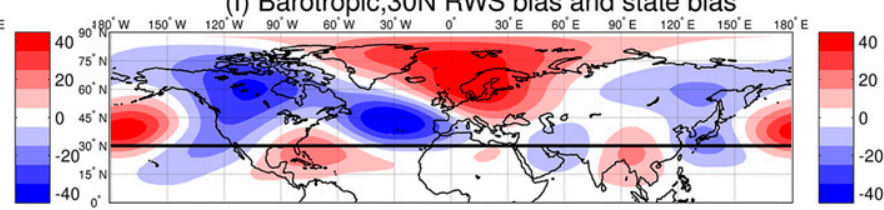

FIG. 9. Responses to the El Niño Rossby wave source bias on same basic states, and also with both RWS bias and state bias included. Differences in barotropic model Z250 responses (m) using RWS up to (left) $15^{\circ} \mathrm{N}$ and (right) $30^{\circ} \mathrm{N}$. Experiments with the GCM RWS minus reanalysis RWS on (a),(d) reanalysis basic state and (b),(e) the GCM basic state. (c),(f) Experiment with the GCM RWS and the GCM basic state minus reanalysis RWS and reanalysis basic state.

To summarize, we have shown that the major MCA differences are well captured by the $k=2$ and $k=3$ wave components. Through ray tracing and wave making experiments in the barotropic model, we have shown that the MCA biases over the North Pacific and North America can mostly be explained by $k=2$ and $k=3$ Rossby waves propagating to lower latitudes, and with weaker amplitude, in the GCM than in reanalysis.

\section{North Atlantic and European region}

While the barotropic experiments in section 5 can explain most of the Pacific-North American MCA differences, the North Atlantic-European differences are again not as well captured. So far, we have presented barotropic experiments with the same tropical forcing and different basic states. In the North Pacific, the MCA difference can mostly be explained by the North Pacific jet bias with the same tropical forcing. This result is not too sensitive to whether RWS is imposed up to $15^{\circ}$ or $30^{\circ} \mathrm{N}$, or whether the RWS is from reanalysis or the GCM (not shown). Instead, as we will show now, in the North Atlantic-European region the MCA difference mostly results from different tropical Atlantic wave forcing rather than differences in the jet basic state.

Figure $2 \mathrm{f}$ is suggestive of a wave emanating from the western tropical Atlantic. The tropical Atlantic has been known to affect ENSO teleconnections in this region, for example during late autumn ENSO teleconnections (Ayarzagüena et al. 2018), or during strong El Niño cases (Toniazzo and Scaife 2006; Hardiman et al. 2019), which we shall discuss in section 8 . The basic state bias in the North Atlantic is much smaller than the North Pacific (Fig. 1), resulting in very similar waveguides $\left(K_{s}\right.$ contours in Fig. 6). Poleward of $15^{\circ} \mathrm{N}$, the GCM RWS shows a large area of negative RWS bias over the Caribbean compared to reanalysis (Fig. 7c). We investigate whether this RWS bias could explain the MCA difference in the North Atlantic-European region.

Figures 9a, 9b, 9d, and 9e show barotropic model geopotential height response differences between experiments using the same basic state but different RWS. Figure 9a shows the response of an experiment using $15^{\circ} \mathrm{N}-15^{\circ} \mathrm{S}$ GCM RWS and reanalysis basic state, minus the response using $15^{\circ} \mathrm{N}-15^{\circ} \mathrm{S}$ reanalysis RWS and reanalysis basic state. The difference is weaker in both the North Pacific and the North Atlantic than that from using the same $15^{\circ} \mathrm{N}-15^{\circ} \mathrm{S}$ reanalysis RWS and different basic states (Fig. 8c), showing that when only RWS up to $15^{\circ} \mathrm{N}$ is used, the extratropical response is more sensitive to the basic state bias than the RWS bias.

However, using RWS bias up to $30^{\circ} \mathrm{N}$ while keeping the reanalysis basic state produces strong response differences (Fig. 9d), and suggests a wave emanating from the Caribbean that propagates across the North Atlantic and reaches Scandinavia. The higher heights in the Caribbean are consistent with the local negative RWS bias in Fig. 7c. Figure 9d shows a Rossby wave propagating from the Caribbean into the North Atlantic and across Scandinavia into Russia. The higher heights over western Russia and the lower heights over eastern Russia mostly agree with those in the MCA difference (Fig. 2f). Although the higher heights in the Caribbean and the lower heights in the North Atlantic in this 
(a) GCM climatological RWS bias

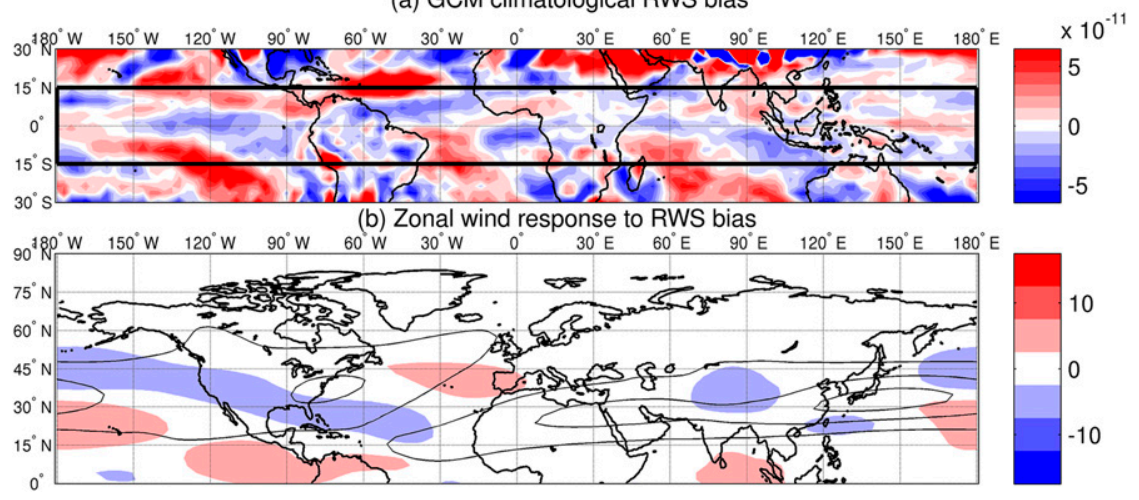

FIG. 10. Zonal wind response to Rossby wave source climatological bias. (a) The climatological bias of the GCM RWS $\left(\mathrm{s}^{-2}\right)$, with the black box showing the latitudes used as forcing in the barotropic experiment. (b) The $250-\mathrm{hPa}$ zonal wind response $\left(\mathrm{m} \mathrm{s}^{-1}\right)$ from this forcing in a barotropic experiment using reanalysis basic state. The black contour shows the reanalysis climatology, in $20 \mathrm{~m} \mathrm{~s}^{-1}$ intervals from $20 \mathrm{~m} \mathrm{~s}^{-1}$.

barotropic experiment (Fig. 9d) are in slightly different locations compared to the MCA difference (Fig. 2f), one possible reason is the strong eddy-mean flow interactions of this wave with the North Atlantic storm track (e.g., Lau 1988), which are not captured by the barotropic model. Therefore, the North Atlantic wavelike pattern in the MCA difference can partly be explained by a wave propagating from the RWS bias in the Caribbean. The results are similar if instead the GCM basic states are used (Figs. 9b,e), showing that the RWS bias is more important than the basic state bias in explaining the North Atlantic-European wave pattern. In the two experiments with $30^{\circ} \mathrm{N}$ RWS bias and unchanged basic states (Figs. 9d,e), the lower heights in central North America in the MCA difference in Fig. $2 \mathrm{f}$ are not reproduced. This is consistent with our earlier conclusion that the basic state bias is more important than the RWS bias for explaining the MCA difference in North America.

Figures 9c and 9f show barotropic model geopotential height response differences between experiments using different basic states and different RWS. For example, to generate Fig. 9c, we perform an experiment using the basic state and the RWS both from the GCM, and subtract from it the response of an experiment using the basic state and the RWS both from the reanalysis. The response in Fig. 9c is similar to that just using reanalysis RWS but different basic states in Fig. 8c, showing that the $15^{\circ} \mathrm{N}$ RWS bias is not as important as the basic state bias. When the RWS bias is included up to $30^{\circ} \mathrm{N}$ and with the basic state bias also included (Fig. 9f), the central North American response is better reproduced, again showing the importance of the basic state bias for reproducing the MCA difference in this region.
A caveat is that we have to force up to $30^{\circ} \mathrm{N}$ to see this result. The imposed Rossby wave source at this latitude may be strongly affected by the extratropical circulation anomalies themselves, and so does not necessarily represent a simple influence of the tropics on the midlatitudes. However, another possibility is that the North Pacific jet bias, in particular its zonality over the eastern North Pacific, likely also affects how synoptic waves propagate into the North Atlantic or the tropical Atlantic (Drouard et al. 2015). Subsequent interactions from such synoptic waves in the tropical Atlantic may cause such RWS bias. For example, these different wave propagations may affect the SST gradient and affect the North Atlantic storm track, which has a climatological entrance just north of the Caribbean.

\section{Possible cause of the jet bias}

So far, we have yet to discuss the possible cause of the North Pacific jet bias. Under the framework of tropicalextratropical teleconnections, we investigate whether the tropics could play a role in the jet bias. Figure 10a shows the climatological mean RWS bias of the GCM minus reanalysis. We perform two barotropic model experiments both with the reanalysis basic state. One experiment uses the climatological RWS from the reanalysis applied up to $15^{\circ} \mathrm{N}$, and the other experiment uses the climatological RWS from the GCM applied up to $15^{\circ} \mathrm{N}$. Figure $10 \mathrm{~b}$ shows the difference in the $250-\mathrm{hPa}$ zonal wind responses. In the North Pacific, it shows weakened winds at around $45^{\circ} \mathrm{N}$ and strengthened winds around $25^{\circ} \mathrm{N}$, indicating an equatorward jet shift. This resembles the GCM jet bias (Fig. 1), although the response is at a slightly lower latitude than the GCM jet 
bias and is weaker. Over North America and the North Atlantic, the response is too equatorward and resembles less the GCM jet bias. Therefore, the climatological GCM RWS bias in the tropics is consistent with some of the North Pacific jet bias.

To put our result into context with the driving mechanisms of the winter jets, it is well known that the subtropical jet is largely driven by momentum export from the tropics, and the polar jet results from converging eddy momentum fluxes. While our barotropic experiment does not explicitly contain these two mechanisms, our result suggests that the climatological tropical RWS bias can drive a wavelike response that projects onto the jet bias. However, our result alone does not provide definitive evidence of this, because the jet bias may also project onto the climatological tropical RWS to result in a climatological RWS bias consistent with the jet bias.

The GCM North Pacific jet bias is a feature of long, free-running coupled runs of this climate model and is not as severe in the seasonal hindcasts from the same GCM (Scaife et al. 2017; Williams et al. 2017). As these hindcasts are initialized near the beginning of each season, there may not be enough time for such a jet bias to develop within the season. Also, the SSTs are closer to reality, so it is likely that coupled processes are involved in the establishment of the bias. Dawson et al. (2013) showed that a coupled model with lower oceanic horizontal resolution cannot resolve small-scale processes and produces a less realistic oceanic mean state, which allows the atmospheric model component to be forced less realistically, producing an atmospheric mean state bias. It is possible that the climatological RWS bias in our studied GCM may have come from the oceanic component.

\section{Conclusions and discussion}

We began by relating the leading mode of tropicalextratropical covariability in Northern Hemisphere winter to El Niño. Comparing the leading mode between reanalysis and the GCM showed similar tropical OLR patterns but less similar extratropical circulation patterns. There are two major factors that can affect tropical-extratropical teleconnections: differences between basic states, and differences between RWS. We showed that the circulation difference in the PacificNorth American region can mostly be explained by basic state differences. Rossby waves from identical tropical RWS propagate differently under the North Pacific jet bias in the GCM, resulting in a different extratropical response which is similar to the MCA difference.

The idea that upper-level zonal wind biases can affect Rossby wave propagation in earlier versions of the Met
Office coupled models has been investigated by Dawson et al. (2011). They suggested that the incorrect extratropical SST response to El Niño in the coupled model is related to different Rossby wave propagation due to subtle biases in the basic state zonal winds. Dawson et al. (2013) also showed that the basic state bias can be accounted for by SST biases due to lower ocean resolution. Here, we update these previous studies to the nextgeneration GCM. We show that although the GCM has undergone development since these earlier studies, basic state biases still remain and have significant dynamical consequences. Second, we demonstrate the different wave propagation using a hierarchy of stationary Rossby wave propagation models, from ray tracing to barotropic model.

Besides tropical forcing, it is well known that internal and chaotic variability can also partly drive extratropical circulation variability. For example, this has been demonstrated by Ding et al. (2011) even for the leading MCA circulation mode in the Northern Hemisphere summer. The tropical forcing observed in the OLR pattern could just be sufficient to trigger some normal modes in the extratropics. Furthermore, eddy-mean flow feedbacks may also play a role on the interannual time scale, by shaping the circulation anomalies. In the storm track regions, the large-scale flow anomalies are strongly affected by systematic heat and momentum fluxes associated with the transient baroclinic eddies (e.g., Robinson 1991; Feldstein and Lee 1998). Altered eddy behavior in response to remote forcing can provide important feedbacks that modulate the large-scale circulation response (e.g., Kug and Jin 2009; Hall and Derome 2000; Kang et al. 2011). It is important to note that this feedback is not included in the barotropic model used in this study. Another limitation of the barotropic model is that it represents the atmosphere as a single level, while Rossby waves in reality propagate on a three-dimensional background state. Despite these limitations, we have found the model to be of use in investigating the sensitivity of waves to the background state.

In contrast to our conclusion that the Pacific-North American MCA difference can mostly be explained by the jet bias, we show that the North Atlantic-European MCA difference can mostly be explained by the tropical RWS bias. The MCA difference is similar to a wave propagating from a GCM RWS bias in the Caribbean, and the Atlantic response is not sensitive to the basic state. Other studies also support the importance of the Caribbean as a wave source affecting the North AtlanticEuropean region (Manola et al. 2013; Knight et al. 2017), although not in an ENSO context. While the cause of our Caribbean RWS bias is inconclusive, it is possibly 
related to the downstream development of different wave propagation from North America due to the North Pacific jet bias. We also show that the North Pacific jet bias is partly consistent with the model climatological tropical RWS bias.

To directly compare our reanalysis MCA to the El Niño pattern, we regress the reanalysis OLR and Z500 onto the standardized Niño-3.4 index to obtain the El Niño OLR and Z500 patterns, respectively. The only difference between our MCA Z500 and the El Niño $\mathrm{Z} 500$ is that there is a ridge over Europe $\left(0^{\circ}, 45^{\circ} \mathrm{N}\right)$ in the MCA Z500 but almost no signal in the El Niño Z500 (not shown). In the tropics, the MCA OLR is just about $10 \%$ stronger. Therefore, our MCA patterns are mostly capturing the El Niño teleconnection. The strongest extratropical signal in the reanalysis MCA Z500 pattern is the Aleutian low. This, together with the downstream dipole across Canada and the North Atlantic is not exactly the PNA pattern, as can be seen by the eastward shift of the MCA pattern with respect to the standard PNA, and that the correlation with the PNA index is only 0.67 (Table 1). The MCA Z500 pattern in this region is more related to the El Niño extratropical pattern, which has been suggested to be distinct from the PNA in both the spatial structure and probability distribution (Straus and Shukla 2002).

King et al. (2018) showed that the ENSO teleconnection pattern exhibits intraseasonal changes between November and the next February. In November, the teleconnection is strong over the North Atlantic and Europe, with the El Niño teleconnection resembling the positive east Atlantic (EA) teleconnection pattern. Ayarzagüena et al. (2018) suggested that this pattern originates from a tropical Atlantic RWS. Although the tropical Pacific SST anomalies are already strong in autumn, the Rossby wave forced by ENSO over the North Pacific and North America is not fully established until January. In December, the EA weakens and anomalies in the North Pacific and America strengthen. In January and February, a Rossby wave develops fully over the North Pacific and North America, while the signal over the North Atlantic-Europe region becomes weak and indistinct. When we perform the MCA on the individual months using reanalysis, for November the Z500 leading mode pattern is similar to the EA pattern in the North Atlantic, with weak amplitudes in the North Pacific, in agreement with King et al. (2018). For December, anomalies in the extratropical Pacific strengthen and the EA weakens, and a $k=3$ wave pattern emerges. In January, it resembles our DJF pattern in Fig. 2b. Therefore, our DJF seasonal pattern captures mostly the January El Niño teleconnection in both the North Pacific and the North Atlantic.
Regarding the North Atlantic, the ENSO teleconnection over this region is not linear in ENSO amplitude. Focusing on the North Atlantic and Europe in January and February, Toniazzo and Scaife (2006) found a nonlinear response to El Niño that changed pattern over the eastern North Atlantic as the amplitude of the El Niño anomaly increases. While the response of moderate El Niño cases projects onto the negative phase of the NAO, the strong cases do not. Instead, the response in the strong cases is high pressure over the east Atlantic and western Europe similar to a negative EA, but it also extends into the northwestern North Atlantic where the EA should have no signal. Toniazzo and Scaife (2006) suggested that the strong case response can be due to tropospheric Rossby wave propagation from a tropical Atlantic RWS. This suggests agreement with our result that the North Atlantic-European region can be affected by a Caribbean wave during ENSO. Ineson and Scaife (2009) explained the observed intraseasonal transition of moderate El Niño over the Euro-Atlantic region through stratospheric processes, from the positive EA in November and December to the negative NAO in January and February. Our February reanalysis MCA shows a negative NAO pattern, in agreement with this late winter NAO response in moderate El Niño. Our DJF reanalysis MCA pattern (Fig. 2b) has the moderate El Niño feature of lower heights in the central North Atlantic. However, it also has the strong El Niño feature of higher heights in western Europe and lower heights in Greenland. Therefore, our pattern over the North Atlantic-European region is a mixture of the moderate and strong El Niño events as studied in the literature.

Our results for the Met Office GCM can have wider implications than just for one GCM. In the CMIP5 historical runs, the North Pacific jet mean latitude shows large differences across models (Barnes and Polvani 2013), and some jet biases are also present in the North Atlantic and the Southern Hemisphere. Therefore, jet biases are quite common across different models and different basins.

Biases in coupled GCMs are often investigated by applying diagnostics to the complex model and then referring to theoretical concepts for explanation. However, given the complex coupled nature of many biases this approach has serious limitations. For example, it is difficult to separate the contributions of the jet bias and the RWS bias to the El Niño bias just by looking at the GCM, and to compare the importance of the contributions. Our study tries to overcome these limitations by isolating the linear effect of the jet bias and of the RWS bias. In the case we have focused on, these have had qualitative rather than quantitative success but this is still of value. Our understanding of the observed 
and modeled teleconnections can be deepened by information on which features can be explained by the linear approaches taken here and which cannot.

To conclude, this study suggests that climate model biases in the North Pacific atmospheric basic state that develop beyond the seasonal time scale can significantly affect the covarying pattern of El Niño in the Pacific-North American region, through altered propagation of stationary tropospheric barotropic Rossby waves. It is possible that different downstream propagation of these waves into the Caribbean can result in different Rossby wave source in the Caribbean, which we have shown can trigger an anomalous Rossby wave that propagates into the North Atlantic-European region. Therefore during El Niño events, the North Pacific jet bias can have global dynamical consequences.

Acknowledgments. We thank the four anonymous reviewers whose comments have improved this manuscript. We acknowledge the interpolated OLR data and the NCEP Reanalysis 2 data provided by the NOAA/ OAR/ESRL PSD, Boulder, Colorado, USA, from their web site at https://www.esrl.noaa.gov/psd/. We acknowledge the CPC for the PNA index from their web site https://ftp.cpc.ncep.noaa.gov/wd52dg/data/indices/pna index.tim, and the Niño-3.4 index from their web site http:// origin.cpc.ncep.noaa.gov/products/analysis_monitoring/ ensostuff/detrend.nino34.ascii.txt. We acknowledge the Met Office and Robert Lee for providing the GCM data. This study was funded by the NERC IMPETUS project (NE/L01047X/1). CO was funded by the NERC SummerTIME project (NE/M005887/1). AAS was supported by the joint U.K. BEIS/Defra Met Office Hadley Centre Climate Programme (GA01101). The research materials supporting this publication can be accessed by contacting the corresponding author.

\section{REFERENCES}

Alexander, M. A., I. Bladé, M. Newman, J. R. Lanzante, N.-C. Lau, and J. D. Scott, 2002: The atmospheric bridge: The influence of ENSO teleconnections on air-sea interaction over the global oceans. J. Climate, 15, 2205-2231, https://doi.org/10.1175/15200442(2002)015<2205:TABTIO >2.0.CO;2.

Athanasiadis, P. J., and Coauthors, 2017: A multisystem view of wintertime NAO seasonal predictions. J. Climate, 30, 14611475, https://doi.org/10.1175/JCLI-D-16-0153.1.

Ayarzagüena, B., S. Ineson, N. J. Dunstone, M. P. Baldwin, and A. A. Scaife, 2018: Intraseasonal effects of El Niño-Southern Oscillation on North Atlantic climate. J. Climate, 31, 88618873, https://doi.org/10.1175/JCLI-D-18-0097.1.

Barnes, E. A., and L. Polvani, 2013: Response of the midlatitude jets, and of their variability, to increased greenhouse gases in the CMIP5 models. J. Climate, 26, 7117-7135, https://doi.org/ 10.1175/JCLI-D-12-00536.1.
Bell, C. J., L. J. Gray, A. J. Charlton-Perez, M. M. Joshi, and A. A. Scaife, 2009: Stratospheric communication of El Niño teleconnections to European winter. J. Climate, 22, 4083-4096, https://doi.org/10.1175/2009JCLI2717.1.

Benjamini, Y., and Y. Hochberg, 1995: Controlling the false discovery rate: A practical and powerful approach to multiple testing. J. Roy. Stat. Soc., 57B, 289-300, https://doi.org/ 10.1111/j.2517-6161.1995.TB02031.X.

Chiodi, A. M., and D. E. Harrison, 2015: Global seasonal precipitation anomalies robustly associated with El Niño and La Niña events-An OLR perspective. J. Climate, 28, 6133-6159, https://doi.org/10.1175/JCLI-D-14-00387.1.

Dai, A., and T. M. L. Wigley, 2000: Global patterns of ENSOinduced precipitation. Geophys. Res. Lett., 27, 1283-1286, https://doi.org/10.1029/1999GL011140.

Dawson, A., A. J. Matthews, and D. P. Stevens, 2011: Rossby wave dynamics of the North Pacific extra-tropical response to El Niño: Importance of the basic state in coupled GCMs. Climate Dyn., 37, 391-405, https://doi.org/10.1007/s00382-010-0854-7.

,,,--- M. J. Roberts, and P. L. Vidale, 2013: Importance of oceanic resolution and mean state on the extra-tropical response to El Niño in a matrix of coupled models. Climate Dyn., 41, 1439-1452, https://doi.org/10.1007/s00382-012-1518-6.

Ding, Q., B. Wang, J. M. Wallace, and G. Branstator, 2011: Tropical-extratropical teleconnections in boreal summer: Observed interannual variability. J. Climate, 24, 1878-1896, https://doi.org/10.1175/2011JCLI3621.1.

Drouard, M., G. Rivière, and P. Arbogast, 2015: The link between the North Pacific climate variability and the North Atlantic Oscillation via downstream propagation of synoptic waves. J. Climate, 28, 3957-3976, https://doi.org/10.1175/JCLI-D-14-00552.1.

Feldstein, S., and S. Lee, 1998: Is the atmospheric zonal index driven by an eddy feedback? J. Atmos. Sci., 55, 3077-3086, https:// doi.org/10.1175/1520-0469(1998)055<3077:ITAZID>2.0.CO;2.

Hall, N. M. J., and J. Derome, 2000: Transience, nonlinearity, and eddy feedback in the remote response to El Niño. J. Atmos. Sci., 57, 3992-4007, https://doi.org/10.1175/1520-0469(2001) 058<3992:TNAEFI $>2.0 . \mathrm{CO} ; 2$.

Hardiman, S. C., N. J. Dunstone, A. A. Scaife, D. M. Smith, S. Ineson, J. Lim, and D. Fereday, 2019: The impact of strong El Niño and La Niña events on the North Atlantic. Geophys. Res. Lett., 46, 2874-2883, https://doi.org/10.1029/2018GL081776.

Hoerling, M. P., A. Kumar, and M. Zhong, 1997: El Niño, La Niña, and the nonlinearity of their teleconnections. J. Climate, 10, 1769-1786, https://doi.org/10.1175/1520-0442(1997)010<1769: ENOLNA $>2.0 . \mathrm{CO} ; 2$.

Hoinka, K. P., 1998: Statistics of the global tropopause pressure. Mon. Wea. Rev., 126, 3303-3325, https://doi.org/10.1175/15200493(1998)126<3303:SOTGTP>2.0.CO;2.

Hoskins, B. J., and D. J. Karoly, 1981: The steady linear response of a spherical atmosphere to thermal and orographic forcing. J. Atmos. Sci., 38, 1179-1196, https://doi.org/10.1175/15200469(1981)038<1179:TSLROA > 2.0.CO;2.

_ , and T. Ambrizzi, 1993: Rossby wave propagation on a realistic longitudinally varying flow. J. Atmos. Sci., 50, 1661-1671, https:// doi.org/10.1175/1520-0469(1993)050<1661:RWPOAR > 2.0.CO;2.

Huang, B., and Coauthors, 2015: Extended Reconstructed Sea Surface Temperature version 4 (ERSST.v4). Part I: Upgrades and intercomparisons. J. Climate, 28, 911-930, https://doi.org/ 10.1175/JCLI-D-14-00006.1.

Ineson, S., and A. A. Scaife, 2009: The role of the stratosphere in the European climate response to El Niño. Nat. Geosci., 2, 32-36, https://doi.org/10.1038/ngeo381. 
Kanamitsu, M., W. Ebisuzaki, J. Woollen, S.-K. Yang, J. J. Hnilo, M. Fiorino, and G. L. Potter, 2002: NCEP-DOE AMIP-II Reanalysis (R-2). Bull. Amer. Meteor. Soc., 83, 1631-1644, https://doi.org/10.1175/BAMS-83-11-1631.

Kang, I.-S., J.-S. Kug, M.-J. Lim, and D.-H. Choi, 2011: Impact of transient eddies on extratropical seasonal-mean predictability in DEMETER models. Climate Dyn., 37, 509-519, https:// doi.org/10.1007/s00382-010-0873-4.

Kiladis, G. N., and K. M. Weickmann, 1992: Extratropical forcing of tropical Pacific convection during northern winter. Mon. Wea. Rev., 120, 1924-1939, https://doi.org/10.1175/15200493(1992) $120<1924$ :EFOTPC $>2.0$.CO;2.

— tropics in two GFDL general circulation models. Climate Dyn., 9, 245-252, https://doi.org/10.1007/BF00208256.

King, M. P., I. Herceg-Bulić, I. Bladé, J. García-Serrano, N. Keenlyside, F. Kucharski, C. Li, and S. Sobolowski, 2018: Importance of late fall ENSO teleconnection in the Euro-Atlantic sector. Bull. Amer. Meteor. Soc., 99, 1337-1343, https://doi.org/10.1175/BAMS-D-170020.1

Knight, J. R., and Coauthors, 2017: Global meteorological influences on the record UK rainfall of winter 2013-14. Environ. Res. Lett., 12, 074001, https://doi.org/10.1088/17489326/aa693c.

Kug, J.-S., and F.-F. Jin, 2009: Left-hand rule for synoptic eddy feedback on low-frequency flow. Geophys. Res. Lett., 36, L05709, https://doi.org/10.1029/2008GL036435.

Lau, N.-C., 1988: Variability of the observed midlatitude storm tracks in relation to low-frequency changes in the circulation pattern. J. Atmos. Sci., 45, 2718-2743, https://doi.org/10.1175/ 1520-0469(1988)045<2718:VOTOMS > 2.0.CO;2.

Li, Y., J. Li, F.-F. Jin, and S. Zhao, 2015: Interhemispheric propagation of stationary Rossby waves in a horizontally nonuniform background flow. J. Atmos. Sci., 72, 3233-3256, https:// doi.org/10.1175/JAS-D-14-0239.1.

Liebmann, B., and D. L. Hartmann, 1984: An observational study of tropical-midlatitude interaction on intraseasonal time scales during winter. J. Atmos. Sci., 41, 3333-3350, https://doi.org/ 10.1175/1520-0469(1984)041<3333:AOSOTI>2.0.CO;2.

_ , and C. A. Smith, 1996: Description of a complete (interpolated) outgoing longwave radiation dataset. Bull. Amer. Meteor. Soc., 77, 1275-1277, http://www.jstor.org/stable/26233278.

Manola, I., R. J. Haarsma, and W. Hazeleger, 2013: Drivers of North Atlantic oscillation events. Tellus, 65A, 19741, https:// doi.org/10.3402/tellusa.v65i0.19741.

North, G. R., T. L. Bell, R. F. Cahalan, and F. J. Moeng, 1982: Sampling errors in the estimation of empirical orthogonal functions. Mon. Wea. Rev., 110, 699-706, https://doi.org/ 10.1175/1520-0493(1982)110<0699:SEITEO > 2.0.CO;2.

O'Reilly, C. H., T. Woollings, L. Zanna, and A. Weisheimer, 2018: The impact of tropical precipitation on summertime Euro-Atlantic circulation via a circumglobal wave train. J. Climate, 31, 64816504, https://doi.org/10.1175/JCLI-D-17-0451.1.

$[,-, \ldots$, and $-2019:$ An interdecadal shift of the extratropical teleconnection from the tropical Pacific during boreal summer. Geophys. Res. Lett., 46, 13 379-13 388, https:// doi.org/10.1029/2019GL084079.

Robinson, W. A., 1991: The dynamics of the zonal index in a simple model of the atmosphere. Tellus, 43A , 295-305, https:// doi.org/10.3402/tellusa.v43i5.11953.

Sardeshmukh, P. D., and B. J. Hoskins, 1988: The generation of global rotational flow by steady idealized tropical divergence. J. Atmos. Sci., 45, 1228-1251, https://doi.org/10.1175/15200469(1988)045<1228:TGOGRF $>2.0$. CO;2.

Scaife, A. A., and Coauthors, 2014: Skillful long-range prediction of European and North American winters. Geophys. Res. Lett., 41, 2514-2519, https://doi.org/10.1002/2014GL059637. , and Coauthors, 2017: Tropical rainfall, Rossby waves and regional winter climate predictions. Quart. J. Roy. Meteor. Soc., 143, 1-11, https://doi.org/10.1002/qj.2910.

Simmons, A. J., 1982: The forcing of stationary wave motion by tropical diabatic heating. Quart. J. Roy. Meteor. Soc., 108, 503534, https://doi.org/10.1002/qj.49710845703.

Straus, D. M., and J. Shukla, 2002: Does ENSO force the PNA? J. Climate, 15, 2340-2358, https://doi.org/10.1175/15200442(2002)015<2340:DEFTP >2.0.CO;2.

Toniazzo, T., and A. A. Scaife, 2006: The influence of ENSO on winter North Atlantic climate. Geophys. Res. Lett., 33, L24704, https://doi.org/10.1029/2006GL027881.

Trenberth, K. E., G. W. Branstator, D. Karoly, A. Kumar, N. Lau, and C. Ropelewski, 1998: Progress during TOGA in understanding and modeling global teleconnections associated with tropical sea surface temperatures. J. Geophys. Res., 103, 14 291-14 324, https://doi.org/10.1029/97JC01444.

Wallace, J. M., C. Smith, and C. S. Bretherton, 1992: Singular value decomposition of wintertime sea surface temperature and 500mb height anomalies. J. Climate, 5, 561-576, https://doi.org/ 10.1175/1520-0442(1992)005<0561:SVDOWS >2.0.CO;2.

Wilks, D. S., 2011: Canonical correlation analysis (CCA). Statistical Methods in the Atmospheric Sciences, D. S. Wilks, Ed., International Geophysics Series, Vol. 100, Academic Press, 563-582, https://doi.org/10.1016/B978-0-12-385022-5.00013-0. 2016: "The stippling shows statistically significant grid points": How research results are routinely overstated and overinterpreted, and what to do about it. Bull. Amer. Meteor. Soc., 97, 2263-2273, https://doi.org/10.1175/BAMS-D-15-00267.1.

Williams, K. D., and Coauthors, 2015: The Met Office Global Coupled Model 2.0 (GC2) configuration. Geosci. Model Dev., 8, 1509-1524, https://doi.org/10.5194/gmd-8-1509-2015.

, and Coauthors, 2017: The Met Office Global Coupled Model 3.0 and 3.1 (GC3.0 and GC3.1) configurations. J. Adv. Model. Earth Syst., 10, 357-380, https://doi.org/10.1002/2017MS001115. 